\title{
Evaluation of internal adaptation of flowable and bulk-fill resin-based composites
}

\author{
Christina Maria Noel ${ }^{1}$, Nor Suhana Azni Satapa ${ }^{1}$, Noor Azlin Yahya ${ }^{2}$, \\ Ros Anita Omar²*
}

\section{KEYWORDS}

Flowable composite, Internal gap formation, Cohesive failure, Adhesive failure, Self-etch adhesive system

\begin{abstract}
This study aimed to evaluate and compare the internal adaptation of bulk-fill resin-based composite restorative materials with flowable composites as lining materials using self-etch adhesive system. Class I cavities $(2 \mathrm{~mm} \times 4 \mathrm{~mm})$ were prepared on flattened occlusal surfaces of fifty extracted human premolars and randomly assigned into five groups ( $n=10)$ according to the materials used: Beautifil Bulk-fill Restorative (BR); Beautifil Bulk-fill Flowable (BF); Beautifil Flow Flowable F10 (BF10); and Self-etch adhesive (SEA). Group A: SEA+BR; Group B: SEA+BF10+BR; Group C: SEA+BF+BR; Group D: SEA+BF10+SEA+BR and Group E: SEA+BF+SEA+BR. The samples were thermocycled for 500 cycles, then sectioned mesiodistally, polished and pre-treated prior to scanning electron microscopy (SEM) evaluation. From SEM images, measurement of adhesive and cohesive adaptation failures was recorded at multiple sites of the pulpal floor and in between materials. Data were analysed using one-way ANOVA and post-hoc Tukey tests $(p<0.05)$. Cohesive failure in SEA was observed at the pulpal floor with the lowest percentage in Group A (5.14\%), and highest in Group C and E (>16\%). However, there were no significant difference among all groups. Adhesive failure was seen at the pulpal floor between $\mathrm{SEA}+\mathrm{BF} / \mathrm{BF} 10 / \mathrm{BR}$ and between SEA+dentine with the highest percentage of gaps formed in Group A between SEA+dentine (6.62\%) and SEA+BR (5.30\%). Nonetheless, no significant differences were observed among all groups with $p=0.89$ and $p=0.70$, respectively. With the use of $B F / B F 10$ at the pulpal floor, adhesive failure was reduced but resulted in increased of cohesive failure. However, both adaptation failures were absent between materials (BF/BF10 and BR) regardless with or without application of SEA.
\end{abstract}

\section{INTRODUCTION}

Composite resins have been widely accepted in restorative dentistry since they were first developed due to their competency of replacing biological tissue not only functionally but also aesthetically [1]. Obtaining good marginal seals in a restoration with composite materials determine long-term success of a restored tooth. This requirement of achieving good marginal seals becomes a major concern for every clinician

${ }^{1}$ Faculty of Dentistry, University of Malaya, Kuala Lumpur 50603, Malaysia.

${ }^{2}$ Department of Restorative Dentistry, Faculty of Dentistry, University of Malaya, Kuala Lumpur 50603, Malaysia.

*Correspondence: anitaomar@um.edu.my because the biggest drawback of composite materials is polymerisation shrinkage. Polymerisation shrinkage is a dimensional shrinkage that occurs during polymerisation reaction of light-cured composite which induces polymerisation contraction stress when a material is placed inside a cavity [2]. The contraction stress has the potential of generating gaps at the toothmaterial interface if the strength exceeds the dentine bond strength. Such gaps are considered deleterious because they allow transmission of fluid or bacteria between the dentine pulp complex and the oral environment, leading to post-operative sensitivity, marginal staining and secondary caries $[3,4,5]$. 
Due to these facts, many methods have been proposed to overcome polymerisation shrinkage. Incremental layering technique has always been one of the ways. Several studies have shown that incremental layering technique ensures satisfactory polymerisation of light-cured composite in deep penetration [6, 7]. However, this incremental layering technique gives rise to problems such as air incorporation, contamination between layers and high stresses at the interfacial margin [8]. As a result, an alternative for this complicated layering technique i.e. bulk-fill composites, has been introduced.

Bulk-fill composites allow placement of a single increment of 4-5 $\mathrm{mm}$ thick and reduced polymerisation time to as low as 20 seconds in a high potency photopolymerisation [9]. Previous study showed that bulk-fill composite resins give better marginal and internal adaptation quality compared to conventional composites [10], and are generally more translucent than multi-layer composite resins which explain why they cure as effective as multi-layering technique [8]. Other study, on the other hand, stated that regardless of any composites used, microleakage was still observed at the tooth-restoration margin but bulkfill composites showed less microleakage compared to others [11].

It was also reported that the use of flowable composite resins as a lining beneath the bulk-fill composites could be an effective method for control of the stress and prevention of the gap formation [12]. In this regard, it was suggested that the lining with flowable composites act as elastic layer that absorb shrinkage stresses during polymerisation shrinkage [12], and the reduced viscosity of the materials allow them to wet the walls of the prepared cavity better [13, 14]. Flowable composites are recommended for the initial increments that serve as cavity liners as the material are readily adaptable to irregularities of the preparation. A conventional composite resin is then placed on top to provide strength and wear resistance. Some in vitro studies on this technique are contradictory [15]. However, the use of flowable composite as a liner under packable composite has shown less leakage compared to hybrid and flowable composite alone [16].

Along with the use of bulk-fill composites and flowable composites as liner, adhesive system plays an important role in obtaining good marginal seal. Two types of adhesive systems which were commonly used were self-etch and total-etch. Selfetching adhesives are believed to prevent post- operative sensitivity compared to total etching system [17]. A study by Gupta et al. (2017) proved that the one-step adhesive system shows less microleakage than the total-etch adhesives. Previously, two main types of adaptation failures namely adhesive and cohesive failures have been observed [19]. Adhesive failures occur either between the adhesive and dentine, or adhesive and composite restoration, while cohesive failures occur when there is internal breakdown of the adhesive itself [20]. The combination of adhesion and cohesion will determine the overall bonding strength in every restoration involving an adhesive and a substrate. However, it seemed that little information is available on internal adaptation of a composite resin restoration using self-etch adhesive system with a flowable composite as lining; therefore, the aim of this study was to evaluate and compare the internal adaptation of bulk-fill composite resin restoration with flowable composites as lining materials, and to evaluate gaps formation between flowable composite and bulkfill composite with and without adhesive. The null hypothesis of this study was that there is no difference in the gap forms between all interfaces at the pulpal floor as well as in between materials, with and without adhesive.

\section{MATERIALS AND METHODS}

In this in-vitro laboratory study, a total of fifty $(n=50)$ human upper premolars, freshly extracted within the time frame of six months either for orthodontic treatment, impacted or periodontal reasons were used. The teeth which were free from caries, restoration or crack, were collected from several clinics in Kuala Lumpur, Malaysia, such as the Faculty of Dentistry, University of Malaya; Bangsar Dental Clinic, Cahaya Suria Dental Clinic, and Smile Partners Dental Clinic. Ethical approval was obtained from the Medical Ethics Committee Faculty of Dentistry, University of Malaya [DF $\mathrm{RD} 1803 / 0011(\mathrm{U})]$ for the use of teeth in this study.

The teeth collected were immediately stored in saline solution at room temperature after extraction. They were disinfected in $0.5 \%$ Chloramine - $\mathrm{T}$ trihydrate solution for a week before being cleaned with ultrasonic scaler to remove any remaining soft tissue and debris. To ensure the teeth were free from caries, cracks or defects, they were examined under stereomicroscope (Olympus, SZX7, Tokyo Japan) at $8 \mathrm{x}$ magnification. The teeth were then stored in distilled water at $4^{\circ} \mathrm{C}$ in the refrigerator until further use. 
The occlusal surfaces of each tooth were flattened with a diamond disc and smoothen with $\# 600$ grit silicon-carbide papers under running water. A standardised Class I cavity $(2 \mathrm{~mm}$ in diameter and 4 $\mathrm{mm}$ in depth) was prepared with carbide bur No. 245 using a high-speed handpiece with water spray. The cavity dimensions were measured using a digital calliper (Mitutoyo Corporation, Kawasaki, Japan) for width, and a periodontal probe for depth. All internal line angles of cavity were rounded and prepared by a single trained operator. The teeth were then randomly divided into five groups (Table 1) and restored with materials (Table 2 ) according to manufacturer's instruction. The composition and type of materials used in this study are presented in Table 2.

Table 1: The five experimental groups of the study

\begin{tabular}{ll}
\hline Group & Description of materials \\
\hline A & Adhesive + Beautifil-Bulk Restorative \\
& (SEA + BR)
\end{tabular}

\begin{tabular}{ll}
\hline B & $\begin{array}{l}\text { Adhesive + liner (Beautifil Flow F10) + } \\
\text { Beautifil Bulk Restorative (SEA + BF10 + } \\
\text { BR) }\end{array}$ \\
\hline C & $\begin{array}{l}\text { Adhesive + liner (Beautifil-Bulk } \\
\text { Flowable) + Beautifil-Bulk Restorative } \\
\\
\text { (SEA + BF + BR) }\end{array}$ \\
\hline D & Adhesive + liner (Beautifil Flow F10) + \\
& adhesive + Beautifil Bulk Restorative \\
& (SEA + BF10 + SEA + BR) \\
\hline E & Adhesive + liner (Beautifil-Bulk \\
& Flowable) + adhesive + Beautifil-Bulk \\
& Restorative (SEA + BF + SEA + BR)
\end{tabular}

The cavity was first cleaned by rinsing thoroughly and air-dried. Self-etchant was applied and scrubbed using a microbrush for 10 s. The cavity was then gently air-dried for $3 \mathrm{~s}$ and more vigorously for another $2 \mathrm{~s}$. This was followed by light curing using a calibrated LED curing light (Bluephase N, Ivoclar Vivadent, Schaan, Liechtenstein) with an output irradiance of $1330 \mathrm{~mW} / \mathrm{cm}^{2}$ and the wavelength range was between $385-515 \mathrm{~nm}$ for $5 \mathrm{~s}$. Light curing tip was placed directly perpendicular and as close as possible to the surface of the composite for each sample. For group A, following the placement of adhesive (SEA), Beautifil-bulk restorative (BR) was placed in single increment and condensed for 20 times using a burnisher, and light cured for $10 \mathrm{~s}$.

For group B, C, D and E, a flowable composite either Beautifil-bulk flowable (BF) or Beautifil flow F10 (BF10) was dispensed until $2 \mathrm{~mm}$ of even thickness was obtained and light cured for 10 s. Prior to placement of BR, SEA was applied once again on top of the flowable liners (BF or BF10) in group D and $E$. Then, BR was placed and condensed for 20 times using a burnisher and light-cured for 10s (Table 1).

Thermocycling was performed between $5^{\circ} \mathrm{C}$ and $55^{\circ} \mathrm{C}$ for 500 cycles using an automated thermocyclic dipping machine (Zecttron, Kuala Lumpur, Malaysia). The dwell time and transfer time were 20 s and 2s, respectively. Samples were stored in an incubator (Memmert Incubator IN750, Germany) at $37^{\circ} \mathrm{C}$ before and after being invested in epoxy resin. The teeth were then sectioned mesiodistally through the centre of each tooth into two fragments with a low-speed water coolant diamond cutter (Isomet 1000, Buhler Ltd, Lake Bluff, IL, USA) at $300 \mathrm{rpm}$. Sectioned samples were smoothened using \#1200 grit silicon-carbide papers (20s/speed $100 \mathrm{rpm}$ ) and ultrasonicated with distilled water for $1 \mathrm{~min}$ to ensure removal of any cutting debris.

The samples were then demineralised using $6 \mathrm{~N} \mathrm{HCL}$ for $1 \mathrm{~min}$, rinsed in distilled water, deproteinised using $6 \% \mathrm{NaOCl}$ for 10 mins, followed by another rinsing with distilled water. The samples were then cleaned with ultrasonic cleaner to completely remove the chemicals. Finally, the samples were dehydrated through an ascending series of ethanol concentrations i.e. from $25 \%$ (20mins), $50 \%$ (20mins), $75 \%$ (20mins), $95 \%$ (30mins), to $99 \%$ (60mins).

The internal gaps formed were then evaluated under scanning electron microscope (SEM) (Low vacuum Operating mode, Model number FEI Quanta 250F) at $10 \mathrm{kV}$, with working distance (WD) of $10 \mathrm{~mm}$. Three images at $\times 1000$ magnification were taken for each sample i.e. at mesial, distal and middle of pulpal floor. For group B, C, D, E three additional images were taken in between two materials used.

\section{Evaluation criteria}

The general aspects of internal gaps at the pulpal floor and in between materials were examined, with particular attention being paid to:

- Gaps formed between BR and dentine (Group A) and flowable composites (BF and BF10) and dentine (Group B, C, D, E)

- Cohesive failure (all groups)

- Gaps formed between BR and flowable composites (BF and BF10), with and without adhesive (Group B, C, D, E) 
Table 2: Materials used in this study

\begin{tabular}{|c|c|c|c|c|}
\hline $\begin{array}{l}\text { Material } \\
\text { (Abbreviation*) }\end{array}$ & Type & $\begin{array}{c}\text { Organic Matrix } \\
\text { (Photo-initiator)/Composition }\end{array}$ & Filler & $\begin{array}{c}\text { Filler \% by } \\
\text { weight/volume }\end{array}$ \\
\hline $\begin{array}{l}\text { Beautifil-Bulk } \\
\text { Restorative } \\
\text { (BR) }\end{array}$ & Giomer & Bis-GMA & S-PRG based on & $87 \%(74.5 \%)$ \\
\hline $\begin{array}{l}\text { Beautifil Flow } \\
\text { Flowable F10 } \\
\text { (BF10) }\end{array}$ & $\begin{array}{c}\text { Giomer } \\
\text { (High Flow) }\end{array}$ & $\begin{array}{c}\text { UDMA } \\
\text { Bis-MPEPP } \\
\text { TEGDMA }\end{array}$ & $\mathrm{F}-\mathrm{Br}-\mathrm{Al}-\mathrm{Si}$ glass & $73 \%$ \\
\hline $\begin{array}{l}\text { Beautifil-Bulk } \\
\text { Flowable } \\
\text { (BF) }\end{array}$ & Giomer & (CQ) & & $73 \%$ \\
\hline $\begin{array}{l}\text { Beauti Bond } \\
\text { (SEA) }\end{array}$ & Self-Etch & $\begin{array}{c}\text { Bis-GMA, } \\
\text { TEGDMA, } \\
\text { HEMA-freephosphonic acid } \\
\text { monomer, carboxylic acid } \\
\text { monomer, acetone, water }\end{array}$ & - & NA \\
\hline
\end{tabular}

Bis-GMA= Bisphenol-A glycidyl methacrylate

Bis-MPEPP $=$ Bisphenol-A polyethoxy-dimethacrylate

$\mathrm{CQ}=$ Camphorquinone

$\mathrm{F}-\mathrm{Br}-\mathrm{Al}-\mathrm{Si}=$ Fluoroboroaluminosiliciate

$N A=$ Not Available

S-PRG = Surface modified pre-reacted glass

TEGDMA = Triethylene glycol dimethacrylate

UDMA $=$ Urethane dimethacrylate

HEMA: 2-hydroxylethyl methacrylate

*Abbreviation depicts the code for study materials

All materials are manufactured by Shofu, Kyoto, Japan

\section{Statistical analysis}

The data obtained were analysed using Statistical Package for the Social Science (version 12.0.1, SPSS Inc., Chicago, USA) for Windows. Descriptive data were expressed as mean [ \pm standard deviation (SD)]. Numeric values were compared using OneWay ANOVA and post-hoc Turkey test for multiple comparisons. The differences were considered statistically significant at $p<0.05$.

\section{RESULTS}

The mean of internal gaps formed is displayed in Table 3, 4 and 5 respectively. Statistical analysis was performed using One-Way ANOVA at 95\% confidence interval. No significant differences were evident on the internal gaps formed in between SEA and $B R$ (Group $A$ ) and between liner or flowable composites and SEA in Group B, C, D, and E, at the pulpal floor $(p=0.89$ ) (Table 3). Likewise, statistically no significant difference $(p=0.70)$ was seen in the gap formed between SEA-dentine (Table 4) at the pulpal floor for all groups. The results also showed no significant difference $(p=0.11)$ in the cohesive failure in all groups (Table 5). Similarly, SEM images also revealed there were no internal gaps formed in between flowable composite and bulk-fill restorative both with and without the use of adhesive (Figure $2 b$ and Figure 5b). SEM images for all groups i.e. group $A$ to $E$ are shown in Figure 1 to Figure 5 respectively.

Table 3: Percentage of gap form between SEA and $B R$ (Group A) and in between liner (BF and BF10) and SEA (Group B, C, D, E) at the pulpal floor

\begin{tabular}{lll}
\hline Group & Mean (SD) & p-value \\
\hline$A(n=10)$ & $5.30(9.28)$ & \\
\hline$B(n=10)$ & $2.30(3.96)$ & \\
\hline$C(n=10)$ & $3.55(5.94)$ & 0.89 \\
\hline$D(n=10)$ & $2.74(6.20)$ & \\
\hline$E(n=9)$ & $2.82(5.99)$ &
\end{tabular}


Table 4: Percentage of gap form between SEA and dentine at the pulpal floor

\begin{tabular}{lll}
\hline Group & Mean (SD) & p-value \\
\hline$A(n=10)$ & $6.62(7.75)$ & \\
\hline$B(n=10)$ & $3.69(5.85)$ & \\
\hline$C(n=10)$ & $3.55(3.88)$ & 0.70 \\
\hline$D(n=10)$ & $3.85(4.63)$ & \\
\hline$E(n=9)$ & $4.85(3.93)$ & \\
\cline { 1 - 2 } & &
\end{tabular}

*significant if $\mathrm{p}<0.05$

Table 5: Percentage of cohesive failure at the pulpal floor

\begin{tabular}{lll}
\hline Group & Mean (SD) & p-value \\
\hline$A(n=10)$ & $5.14(6.75)$ & \\
\hline$B(n=10)$ & $15.12(12.08)$ & \\
\hline$C(n=10)$ & $16.41(11.04)$ & 0.11 \\
\hline$D(n=10)$ & $12.60(9.27)$ & \\
\hline$E(n=9)$ & $16.60(13.13)$ & \\
\hline
\end{tabular}

*significant if $\mathrm{p}<0.05$

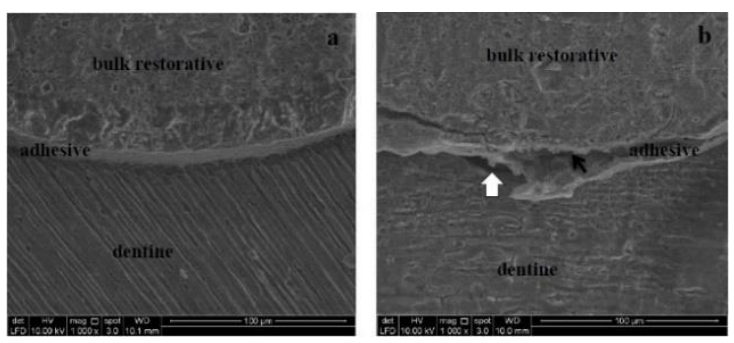

Figure 1: SEM photomicrograph of Group A samples $(S E A+B R)$ : (a) No gap formation was observed at the interface between BR-SEA, SEA-dentine and cohesive failure; (b) The black arrow indicates cohesive failure while the white arrow indicates gap formation between SEA and dentine.

\section{DISCUSSION}

In this recent era, polymerisation shrinkage of composite has been one of the debatable topics among dentists. Polymerisation shrinkage which may eventually lead to generation of shrinkage stress will tend to pull the adhesive from the composite resin, leading to formation of gaps where eventually may allow the penetration of bacteria and causes secondary caries [21].
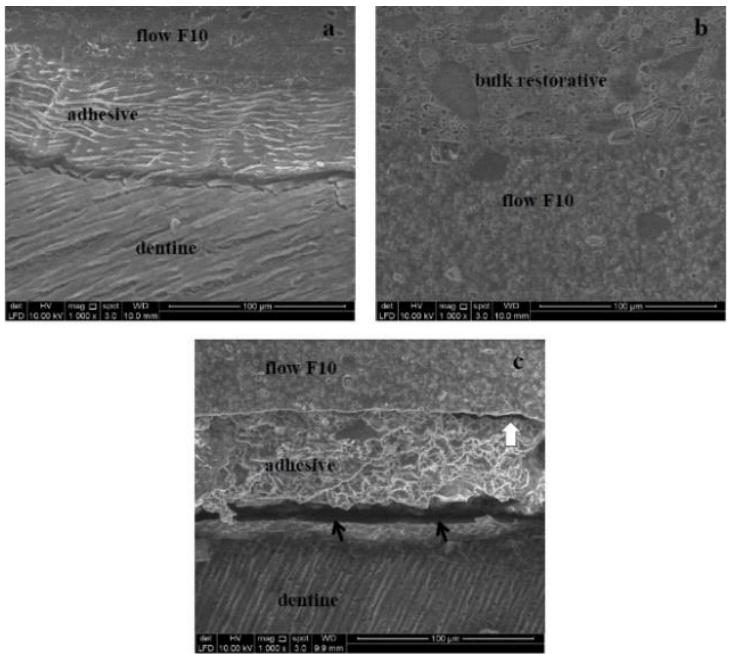

Figure 2: SEM photomicrograph of Group B samples $(\mathrm{SEA}+\mathrm{BF} 10+\mathrm{BR})$. No gap formation was observed at the interface between BF10-SEA, SEA-dentine and cohesive failure (a) and in between BF10 and BR (b). The black arrows indicate cohesive failure while the white arrow indicates gap formation between BF10 and SEA (c).
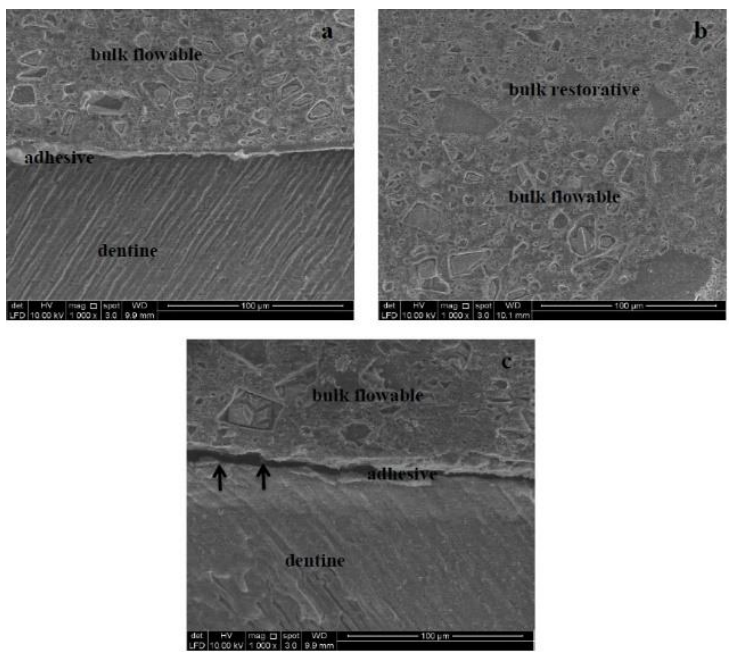

Figure 3: SEM photomicrograph of Group C samples ( $S E A+B F+B R)$. No gap formation was observed at the interface between BF-SEA, SEA-dentine and cohesive failure (a) and in between BF and BR (b) The black arrows indicate cohesive failure (c).

This study could address the main concern of the usage of the flowable composite which is to enhance internal adaptation of composite restoration. Flowable composite was developed to improve fluid injectability from the traditional formulations. Some studies reported a reduction in gap formation when flowable composites were used as intermediate layer due to improved cavity adaptation [14, 21, 22, 23, 24] while some claimed that there was no difference in gap formation with or without flowable composite [25, 26, 27]. Oliveira et al [28] claimed that the use of flowable composite as an intermediate layer would further 
increase the polymerisation shrinkage stress at the adhesive dentine interphase leading to adhesive failure and gaps formation.
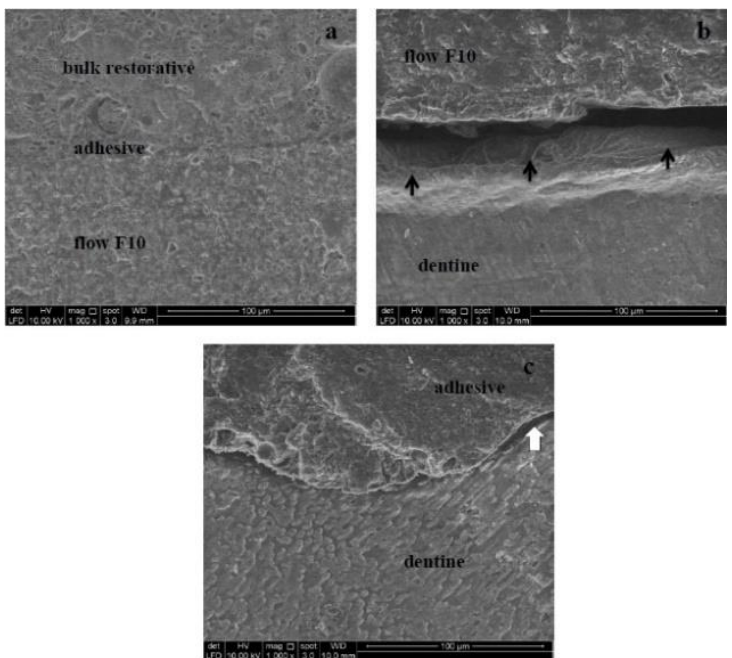

Figure 4: SEM photomicrograph of Group D samples (SEA + BF $10+\mathrm{SEA}+\mathrm{BR})$. No gap formation was observed at the interface between SEA-BF10 and SEA-BR (a). The black arrows indicate cohesive failure (b) while the white arrow indicates gap formation between SEA and dentine (c).
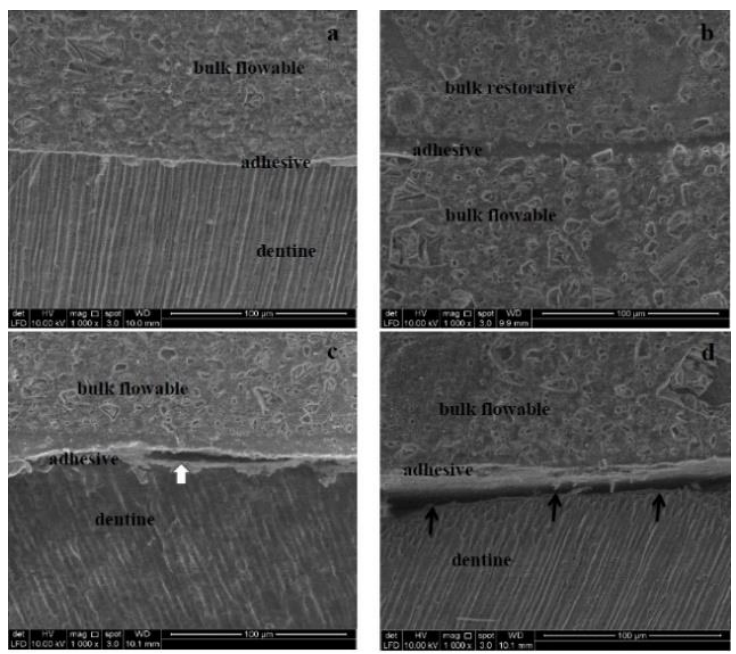

Figure 5: SEM photomicrograph of Group E samples $(S E A+B F+S E A+B R)$. No gap formation was observed at the interface between BF-SEA, SEAdentine and cohesive failure (a) and at the interface in between SEA-BF and SEA-BR (b). The white arrow indicates cohesive failure (c) while the black arrows indicate large gap formation between SEA-dentine interfaces (d).

Modification of sample size Group E has been done as one out of the ten samples showed exceptionally high percentage of gap formation at the adhesivedentine interface which seems inconsistent with the majority of the data set. Subsequently, the initial sample size of fifty was reduced to forty-nine prior to statistical analysis. The outlier was eliminated to improve accuracy of the overall statistical results.

In the present study, the null hypothesis is not rejected since the results showed no significant difference in the gap formation between groups with and without flowable liners. There were also no significant differences between the liner adhesive interface and at the adhesive - dentine interface in Group B, C, D, and E, although the placement of flowable composite does show reduction in the gap formation compared to without liner (Group A); thus the null hypothesis is not rejected.

The reduced in gaps formation in groups with flowable liners could be explained due to the low filler content and low modulus of elasticity of the materials, allowing it to have high flowability and thus demonstrate better adaptation to cavity walls. It is also suggested that liners may act as stressabsorbing layer. A study by Kemp-Scholte and Davidson [29] also stated that the flowable liner acted as a pre-cured layer that gave additional thickness to the pre-existing adhesive layer to absorb stress generated during polymerisation shrinkage thus helping to minimise the gap formation.

Despite all the advantages, decrease in filler content however might be expected to raise another concern due to inferior mechanical properties and higher polymerisation shrinkage when compared to traditional composite [30]. In this study, the use of flowable composite showed increased in cohesive failure. Thus, the null hypothesis is once again not rejected. This could be due to high polymerisation shrinkage of the flowable composite. Polymerisation shrinkage is influenced by many factors, and the amount of shrinkage plays an important role in long-term success of composite restoration. According to Pereira et al [31], the shrinkage of the composite during polymerisation induces contraction stress which can exceed the bond strength, causing gap formation. Their study showed that a higher rate of polymerisation and a higher c-factor tend to cause higher polymerisation shrinkage.

In this study, a single bottle self-etch system was used. It was claimed to have bond strength comparable to current multicomponent brands, however in this present study, we found microgaps formed in the adhesive itself i.e. cohesive failure, and it was higher in the groups with flowable composites. 
The formation of cohesive failure can be explained due to the HEMA content of the adhesive. Beautibond bonding agent (Shofu), is a HEMA-free adhesive. HEMA, a water-soluble methacrylate monomer which is commonly used as one of the constituents in adhesive, plays a role in inhibiting phase separation in all-in-one adhesive system [32]. So, in this system, solvent such as water, acetone and ethanol are blended together with apolar and polar ingredients. The solvent maintains the ingredient in solution, but once dispensed, subsequent evaporation of the solvent can activate phase separation reaction causing formation of multiple voids. Thus, in this study, the lack of HEMA in the adhesive could induce phase separation, and the rapid evaporation of acetone solvent would cause the formation of voids throughout the adhesive layer; hence, the cohesive failure seen in SEA.

Moreover, there has been research demonstrating that, the water concentration in single bond selfetch adhesive influences its bonding efficacy to dentine. Apart from that, the high hydrophilicity of single bottle self-etch adhesive is needed for acid ionisation. However, this may disturb the bonding durability because they tend to attract water. Partial evaporation of water leads to production of microscopic water tubules at the adhesive interfaces. Even though evaporation is successful, water tends to flow back from the bonded dentine through the hybrid and adhesive layers into composite adhesive interface. This occurrence may generate partial polymerisation of the adhesives, causing inferior mechanical properties, which eventually will lead to higher degradation [33, 34]. However, these adaptation gaps could be due to artefact from the high vacuum during preparation for SEM observation or due to desiccation caused from SEM procedure.

\section{CONCLUSION}

Within the limits of this in vitro study, we conclude that when BF or BF10 used at the pulpal floor, the adhesive failure was reduced but cohesive failure is increased. Interestingly, however, no gap was formed i.e. no adaptation failures seen between bulk-fill (BR) and flowable composite (BF and BF10) with and without application of SEA. Unfortunately, the shear bond strength was not measured, thus the strength of the adaptation in between the two materials with and without adhesive could not be evaluated. Thus, further studies are warranted.

From the results gathered, an important note on the clinical significance is that proper application of bonding agent is crucial and essential for a successful adaptation of composite resin restorations to the dentine. The placement of flowable (including bulk flowable) underneath bulk restorative seemed to be not in favour in terms of adaptability.

\section{ACKNOWLEDGEMENT}

This work has been supported by Shofu/Japan and University of Malaya research grant (BKS010-2017). The authors would like to thank Mr. Mohd Zabri Johari for his assistance with the statistical analysis and Mr. Hassan Ismail for his help with the SEM analysis.

\section{DECLARATION OF INTEREST}

The authors declare no conflict of interest.

\section{REFERENCES}

1. Cramer NB, Stansbury JW, Bowman CN. Recent advances and developments in composite dental restorative materials. J Dent Res 2011; 90(4): 402-416.

2. Kumar JS, Jayalakshmi S. Bond failure and its prevention in composite restoration; A review. J Pharm Sci Res 2016; 8(7): 627-631.

3. Bagis $\mathrm{YH}$, Baltacioglu IH, Kahyaogullari S. Comparing microleakage and layering methods of silorane based resin composite in wide Class II MOD cavities. Oper Dent 2009; 34(5): 578-585.

4. Langalia A, Buch A, Khamar M, Patel P. Polymerisation shrinkage of composite resin. J Med Dent Sci Res 2015; 2(10): 23-27.

5. Schneider LFJ, Cavalcante LM, Silikas N. Shrinkage stress generated during resin-composite application: A review. J Dent Biomech 2010; 2010: 1-14.

6. Nikolaenko SA, Lohbauer U, Roggendorf M, Petschelt A, Dasch W, Frankenberger R. Influence of c-factor and layering technique on microtensile bond strength to dentine. Dent Mater 2004; 20(6): 579-585. 
7. Haak R, Wicht MJ. Marginal and internal adaptation of extended Class I restoration lined with flowable composite. J Dent 2003; 31(4): 231-239

8. Alkurdi RM, Abboud SA. Clinical evaluation of Class II composite resin restorations placed by two different bulk-fill techniques. J Dent Orofac Sci 2016; 8(1): 34-39.

9. Barros R, Lins E, Martins LRM. Bulk-fill resin-based composites. Adv Dent Oral Health 2017; 4(5): 1-2.

10. Park SH, Jung JJ, Han SH. Internal and marginal adaptation of bulk filled composite. J Dent Mater 2015; 31(1): 1-66.

11. Gupta SK, Mann NS, Kaur SP, Singh JP. Bulk-fill vs conventional composites: A microleakage study. J Perio Med Clin Prac 2016; 3(3): 122-127.

12. Dauvillier BS, Aarnts MP, Feilzer AJ, Development in shrinkage control of adhesive restorative. J Esthet Dent 2000; 12(6): 291-299.

13. Baig MM, Mustafa M, Al Jaeidi ZA, Muhaiza MA. Evaluation in restoration using different resin composition insertion techniques and liners in preparation with high C-factor. J Dent Sci 2013: 4(2): 57-64.

14. Dionysopoulos D, Papadopoulos C, Koliniotou-koumpia E. The evaluation of various restoration techniques on internal adaptation of composite in Class V cavities. Inter J Biomater 2014: 2014: 1-6.

15. Frankenberger R, Lopes M, Perdgao J, Wallace W, Ambross, Bruno T, Rosa. The use of flowable composites as filled adhesives. J Dent Mater 2002: 18(3): 227-238.

16. Lokhande NA, Padmai AS, Rathore VP, Shingane S, Jayashankar DA, Sharma U. Effectiveness of flowable resin composite in reducing microleakage - An in vitro study. J Inter Oral Health 2014; 6(3): 111-114.

17. Yousaf A, Aman N, Manzoor MA, Shah JA, Dilrasheed. Postoperative sensitivity of self-etch versus total etch adhesive. J College Physic Surg 2014; 24(6): 383-386.

18. Gupta A, Tavane P, Gupta PK, Tejolatha B, Lakhani AA, Tiwari R, Kashyap S, Garg G. Evaluation of microleakage with total etch, self-etch and universal adhesive systems in Class $V$ restorations: An in vitro study. J Clin Diag Res 2017; 11(4): 53-56.

19. Walshaw PR, Tam LE, McComb D. Bond failure at dentin-composite interfaces with 'single-bottle' adhesives. J Dent 2003; 31(2): 117-125.

20. Von Fraunhofer JA. Adhesion and cohesion. International J Dent 2012; 2012: 1-8.

21. Aggrawal V, Sngla M, Yadav S, Yadav H. Effect of flowable composite liner and glass ionomer liner on Class II gingival marginal adaptation of direct composite restorations with different bonding strategies. J Dent 2014; 42(5): 619-625.

22. Sadeghi M, Lynch $C D$. The effects of flowable materials on the microleakage of Class II composite restorations that extend apical to cemento-enamel junction. J Oper Dent 2009; 34(3): 306-311.

23. Korkmaz Y, Ozel E, Attar N. Effect of flowable composite lining on microleakage and internal voids and Class II composite restorations. J Adhes Dent 2007; 9(2): 189-194.

24. Lohande NA, Padmai AS, Rathore VPS, Shinga S, Jayashankar DN, Sharma U. Effectiveness of flowable composite in reducing microleakage- An in vitro study. J Inter Oral Health 2014; 6(3): 111-114.

25. Tanno K, Hiraishi N, Otsuki M, Tagami J. Evaluation of cavity adaptation of low-shrinkage composite resin. Asian Pac J Dent 2011; 11: 27-33.

26. Pecei R, Onisor I, Krejci I, Bortolotto T Marginal adaptation of direct Class II composite restoration with different cavity liners. J Oper Dent 2013; 38(6): 210-220.

27. Han SH, Sadr A, Tagam J, Par SH. internal adaptation of resin composites at two configurations: influence of polymerisation shrinkage and stress. J Dent Mater 2016; 3(2): 1085-1094.

28. Oliveira LCA, Duarte S, Araujo CA, Abrahao A. Effect of low-elastic modulus liner and base as stressabsorbing layer in composite resin restorations. J Dent Mater 2010; 26(3): 159-169.

29. Kemp-Scholte CM, Davidson CL. Complete marginal seal of Class V resin composite restorations effected by increased flexibility. J Dent Res 1990; 69(6): 1240-1243.

30. Baroudi K, Jean C, Rodrigues. Flowable resin composites: A systematic review and clinical consideration. J Clin Diagn Res 2015; 9(6): ZE18-ZE24.

31. Pereira JC, D'Alpino PHP, Lopes LG, Franco EB, Mondelli RFL, Souza JB. Evaluation of internal adaptation of Class $V$ resin composite restorations using three techniques of polymerization. J App Oral Sci 2007; 15(1): 49-54. 
32. Yahagi C, Takagaki T, Sadr A, Ikeda M, Nikaido T, Tagami J. Effect of lining with a flowable composite restorations using all-in-one adhesive systems. J Dent Mater 2012; 31(3): 481-488.

33. Tay FR, Pashley DH. Have dentine adhesives become too hydrophilic? J Can Dent Assoc 2003; 69(11): 726731.

34. Hiraishi N, Nishiyama N, Ikemura K, Yau JYY, King NM, Tagami J, Tay FR. Water concentration in self-etching primers affects their aggressiveness and bonding efficacy to dentin. J Dent Res 2005; 84(7):653-658.

\section{Editorial History}

Date of Submission: 27 Nov 2020

Review \& Revision: 30 Nov 2020 - 19 Jan 2021

Accepted: 17 Feb 2021

Published: 16 April 2021

License Information: This work is licensed under a Creative Commons Attribution 